\title{
Pour un savoir historique du social et du politique
}

\section{Crime et pauvreté à l'ère du libéralisme}

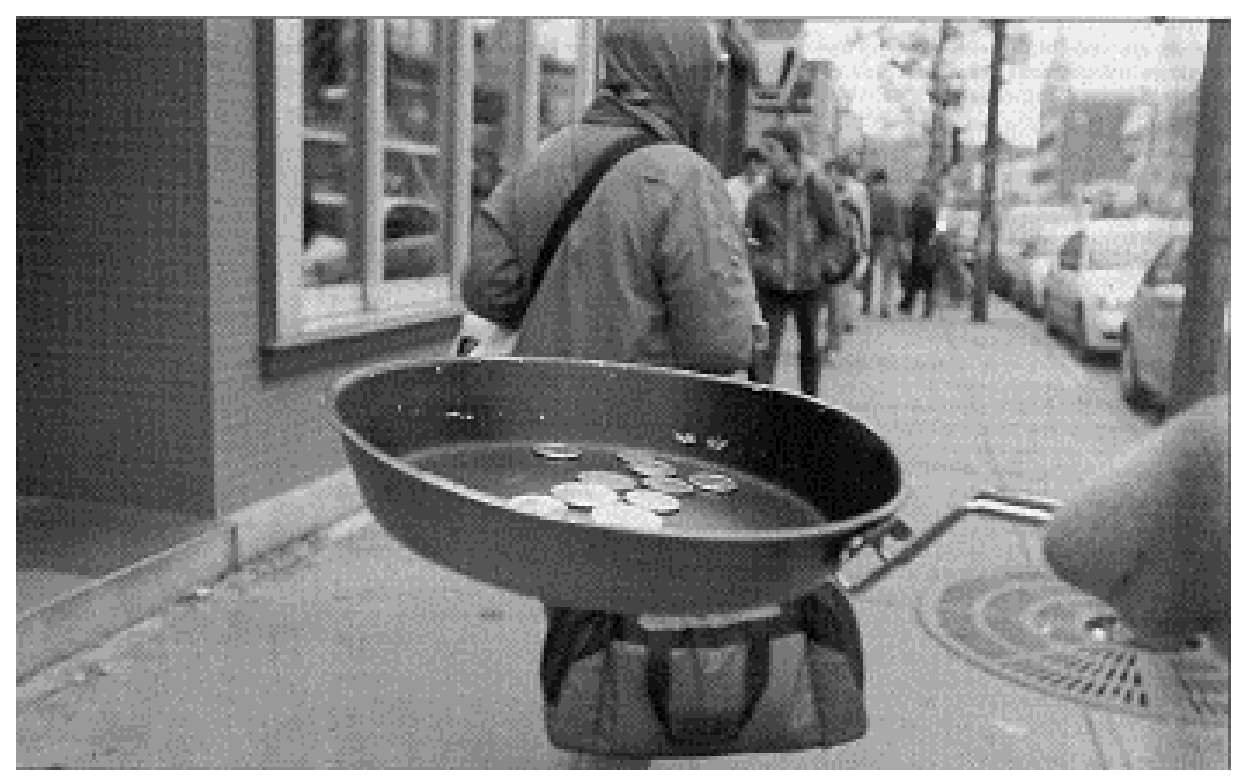

Jean-Marie Fecteau

Professeur au Département d'histoire de l'UQAM et directeur du Centre d'histoire des régulations sociales, chercheur au Centre de recherche sur les innovations sociales (CRISES)

fecteau.jean-marie@uqam.ca

Dans le cadre du congrès de l'ACFAS 2004 qui se tient cette semaine à Montréal, des dizaines de chercheurs de tous horizons feront part des résultats de leurs plus récents travaux. Nous publions cette semaine quelques textes rédigés à notre demande par des chercheurs de l'Université du Québec à Montréal, université d'accueil de l'événement.

Comment une société «tient»-elle ensemble ? Comment est-il possible de penser un savoir-vivre (et un vouloirvivre) collectif se déclinant selon les règles de la démocratie et du libre marché ? Question fondamentale qui hante les sociétés, à partir de ce moment où on a renoncé à faire de Dieu l'explication première et dernière de l'univers, où on a voulu inventer un monde fondé sur la liberté et le respect de l'intégrité des hommes et des femmes qui le composaient. 
En somme, il s'agit de faire sens de ce basculement radical du monde depuis maintenant deux siècles et de saisir les enjeux collectifs fondamentaux qui se sont déployés à partir de l'idée simple d'une liberté humaine vécue dans l'égalité. C'est un tel questionnement fondamental qui est à la source des recherches menées au Centre d'histoire des régulations sociales (www.unites.uqam.ca/chrs/) sur la mise en place du réseau de prise en charge du crime et de la pauvreté au Québec, depuis le milieu du XIXe siècle.

\section{Une immense aspiration au bonheur}

Dans cette entreprise, il nous fallait comprendre des enjeux qui soustendent les formes de régulation sociale mises en place à l'ère libérale et qui, à partir du plus profond du XIXe siècle, accouchent du monde actuel. La stratégie privilégiée pour ce faire implique de ramener ce libéralisme, triomphant au XIXe siècle, à ce qu'il était vraiment : une version limitée, mise au service des possédants, d'une immense aspiration au bonheur issue de l'écroulement brutal du monde ancien.

Ce libéralisme, malgré les parentés étymologiques, n'a nullement le monopole, même à l'époque de son apogée, des diverses solutions envisagées pour assurer un lien social qui soit fondé sur la liberté. Il n'est qu'une version étriquée, en mode mineur, de l'aspiration à la liberté, version soigneusement expurgée de sa dimension collective, des espoirs des dominés, et timidement ramenée au «réalisme» des possédants, puis vite coulée dans le ciment des institutions de régulation et de répression, dans le cadre rigide du droit bourgeois qui en constituera le rempart le plus solide.
Hypothèque close sur l'avenir, qui ouvrira néanmoins à l'Église québécoise un large espace d'action où elle pourra déployer sa puissance, tout en dénonçant ce même libéralisme, pourtant condition première de son expansion possible...

Car, au Québec plus qu'ailleurs peutêtre, derrière l'appareil de l'Église s'est toujours profilée l'injonction libérale du libre marché et de l'État minimal. Nulle part ne peut-on saisir ce modèle contradictoire de société qu'en confrontant le discours libéral, même récupéré et filtré par le rigorisme religieux, à ses pires hantises : le crime et la pauvreté. Le crime, ce constant refus du jeu social gravé dans les codes; la pauvreté, spectacle permanent des inégalités qui révèle l'hypocrisie des discours sur le progrès des peuples.

\section{Que faire de la marge criminelle?}

C'est en étudiant les modes de prise en charge de ces problèmes sociaux fondamentaux, qui transcendent, en suivant leurs lignes de force, les césures fondamentales exprimées par les rapports de classe et de genre, que l'on peut le mieux, je crois, saisir les limites et les culs-de-sac de cette vision du monde, de cet univers institutionnel, de cette échelle de valeurs que constitue le libéralisme bourgeois et ses versions ultérieures.

Ainsi en est-il du crime. Au XIXe siècle, on lui invente la prison comme horizon. D'abord conçue comme instrument de la rémission du criminel (comme si en confinant dans l'espace raréfié de la prison, on pouvait enseigner les jeux et les enjeux de la liberté !), cette dernière est vite devenue le simple non-lieu, le temps 
mort et l'absence absolue d'une liberté vécue comme horizon inatteignable.

Source de toutes les peurs sociales et en même temps manifestation du chaos d'un quotidien souvent insupportable, le crime exprime l'aporie fondamentale de la liberté imaginée par ces «libéraux» dont certains encore aujourd'hui se réclament: une liberté dont les limites dont définies par la volonté des dominants, et où l'infraction est autant témoignage du réel intolérable que du refus de le vivre comme tel.

À partir de ce moment, les sociétés libérales, même à l'ère des États providence, ne sauront que faire de leurs marges criminelles, ballottées entre les pulsions hystériques de la «tolérance zéro» comme des mille guerres aux déviants et les moments utopiques de l'amendement recherché des criminels. Les sociétés carburant à la liberté bourgeoise avaient rêvé de repousser à leurs confins ultimes le résidu social constitué par les criminels. Elles se sont retrouvées toutes entières investies par les pratiques, individuelles et collectives, d'infraction.

\section{Figure d'un échec}

Ainsi en est-il, aussi, de la pauvreté. Comment imaginer qu'une société fondée sur la liberté d'entreprise, ouverte aux mille initiatives et inventions des citoyens, puisse déboucher sur des sociétés inégalitaires, où liberté du riche et liberté du pauvre se traduisent, pour l'un, en droit d'exploiter et, pour l'autre, en volonté de survivre?

La pauvreté, même reprochée constamment à l'individu et ramenée à ses tares personnelles, est l'image vivante de l'échec persistant et récurrent du libéralisme bourgeois à inventer une société meilleure. C'est pourquoi la place du pauvre dans l'économie de ces sociétés, comme dans le discours savant, est l'enjeu d'une lutte féroce de définition et de classement. Car dès le moment où la pauvreté est définie comme problème collectif, elle ouvre un espace politique sans fin où risque de s'étioler l'éthique libérale de la responsabilité personnelle.

Ainsi se découvre une deuxième aporie du libéralisme triomphant: celle où chaque mesure d'aide se heurte à la hantise de la déresponsabilisation, où chaque politique apparaît comme incitation à ne pas jouer le jeu social, mais où, dans le même mouvement, la responsabilité du pauvre pour ce qui lui arrive est toujours indexée sur la solidarité collective.

On aura compris peut-être qu'une telle histoire, malgré ses incursions dans un passé lointain, est terriblement actuelle. Non pas que les leçons du passé, comme une fausse sagesse le proclame trop souvent, soient garantes d'un avenir réussi. Mais le rythme historique saccadé qui a vu s'écrouler le rêve libéral d'une pauvreté disparue, du crime muselé, d'une humanité tirée vers l'avenir radieux promis par le progrès constant, cette histoire d'une promesse volée par les dominants, mérite d'être reconstruite et racontée. Car c'est elle qui a accouché du monde actuel.

N'en déplaise aux nostalgiques d'un certain libéralisme, il arrive que de très vieilles (mauvaises) idées empêchent l'émergence de projets novateurs et libérateurs, riches en devenir. En ce sens, l'histoire est là autant pour nous libérer du passé que pour le prospecter. 